after chemical injury, especially benzene poisoning, ${ }^{5}$ and after chloramphenicol-induced aplasia. ${ }^{6-7}$ Here, too, it may be that an injury which induces hypoplasia of bone marrow is also leukaemogenic, or alternatively that leukaemia develops as a result of an abnormal haemopoietic cell line in a regenerating marrow. In $1967 \mathrm{~W}$. Dameshek ${ }^{8}$ suggested that there might also be a link between leukaemia and paroxysmal nocturnal haemoglobinuria, possibly by the abnormal clone leading to the haemoglobinuria in one patient and leukaemia in another. This speculation of a relationship between the two is supported by recent reports from three different centres on the occurrence of acute granulocytic leukaemia in patients with paroxysmal nocturnal haemoglobinuria. ${ }^{9-11}$ In all three cases the latter condition was diagnosed beyond doubt on the basis of in-vitro tests and had probably been present for three to six years before leukaemia became apparent. In none of the cases had there been a preexisting aplastic anaemia. A history of exposure to possible injurious substances was elicited in only one of the patients, a 58-year-old man who had been receiving isoniazid and $p$-aminosalicylic acid for pulmonary tuberculosis.

The publication of these reports has stimulated Dameshek ${ }^{12}$ to repeat his earlier speculation and to remark that the termination of paroxysmal nocturnal haemoglobinuria as acute leukaemia is reminiscent of a similar course in some cases of myelosclerosis, chronic granulocytic leukaemia, polycythaemia vera, and erythraemic myelosis. In this context it is, perhaps, significant that in paroxysmal nocturnal haemoglobinuria the defect is not confined to the red cells but that leucocyte alkaline phosphatase is unusually low, as it also is in chronic granulocytic leukaemia and in some cases of myelosclerosis with myeloid metaplasia. Dameshek postulates that paroxysmal nocturnal haemoglobinuria could be regarded as a myeloproliferative disorder of the same type as erythraemic myelosis. This interesting suggestion deserves study but requires more substantial evidence. But at least it might be worth while to do a screening serological test for paroxysmal nocturnal haemoglobinuria in all cases of acute leukaemia, and conversely patients with this haemoglobinuria should be closely supervised with the possibility in mind of leukaemia developing.

\footnotetext{
${ }^{1}$ Dacie, J. V., and Lewis, S. M., Practical Haematology, 1968, 4th edition. London, Churchill.

2 Rosse, W. F., and Dacie, J. V., fournal of Clinical Investigation, 1966, 45, 749.

Lewris, S. M., Danon, D., and Marikovsky, Y., British fournal of elogy, 1965, 11, 689.

13, S. M., and Dacie, J. V., British fournal of Haematology, 1967, 13, 236.

- DeGowin, R. L., fournal of the American Medical Association, 1963, 185,748 .

- Cohen, T., and Creger, W. P., American fournal of Medicine, 1967, 43, 762 .

7 Brauer, M. J., and Dameshek, W., New England fournal of Medicine, $1967,277,1003$

- Dameshek, W., Blood, 1967, 30, 251.

Jenkins, D. E., and Hartmann, R. C., Blood, 1969, 33, 274.

10 Holden, D., and Lichtman, H., Blood, 1969, 33, 283.

11 Kaufmann, R. W., Schechter, G. P., and McFarland, W., Blood, 1969, 33, 287

12 Dameshek, W., Blood, 1969, 33, 263.
}

\section{Poisoning Treatment Centres}

In 1962 a committee ${ }^{1}$ set up by the Ministry of Health recommended the designation of district centres for the treatment of poisoning and one specialized poisoning treatment unit within each region. Each district centre was to have a physician in charge specially interested in this field, who could readily call on the services of a consultant anaesthetist or psychiatrist. Last year another official committee, the Hill Committee on the Hospital Treatment of Acute Poisoning, commented ${ }^{2}$ that though the district and regional centres had been designated "so far as we can tell, cases of poisoning continued to be received at any local accident and emergency centre." It also pointed out the inadequacy of the supporting laboratory services and the failure of physicians with a special interest in clinical toxicology to emerge except in a few centres. The report recommended that all accident and emergency departments should be staffed and equipped for dealing with cases of acute poisoning of both adults and children. The centres should also have psychiatric cover and adequate laboratory support.

The Department of Health and Social Security commended the report to regional hospital boards and boards of governors, stating that the full implementation of the recommendations might not be practicable immediately or in all areas, and in

1 Hospital Treatment of Acute Poisoning. Report of the Joint Subcommittee of the Standing Medical Advisory Committee, Ministry of Health and Scottish Home and Health Department, 1968, London. H.M.S.O.

- Emergency Treatment in Hospital of Cases of Acute Poisoning. Report of the Subcommittee of the Standing Medical Advisory Committee of the Central Health Services Council, Ministry of Health. 1962. London. H.M.S.O. any case would be subject to the demands of other hospital services on available reseurces.

This week Dr. Henry Matthew and his colleagues report at p. 489 on the centre at the Edinburgh Royal Infirmary, which functions in the manner recommended by the reports. In fact, since the unit has been in existence for over 90 years, it is likely that the recommendations of both reports were influenced to a large extent by it. This paper should help hospital authorities even though no costing information is supplied. There do, however, appear to be certain developments in the management of these patients which might make a difference in the ease and speed with which regional hospital boards are able to implement the Hill report.

The report recommended that every designated poisoning treatment centre should have associated laboratory facilities for carrying out at least the detection and quantitative estimation of carbon monoxide, alcohol, barbiturates, salicylates and iron in blood, and phenothiazines in urine only qualitatively, at short notice throughout 24 hours. Matthew and his colleagues question the need for such a service for several reasons. Firstly, the actual demand for an emergency request is minimal ( 9 per month average). Secondly, the number of cases in which antidotes for the poisons are available is comparatively few. Thirdly, those cases that do require emergency pathological investigations need principally and preferably electrolyte and blood gas analyses. Fourthly, it is now possible to detect the two commonest drugs taken (barbiturates and salicylates) by simple "side-room " methods. It appears, therefore, that the normal laboratory services associated with accident and emergency departments are adequate to manage these patients. 
The Edinburgh Poisoning Treatment Centre is a selfcontained unit of 20 beds serving a catchment area of 500,000 population. This is twice as large a population as the average accident and emergency department serves. Though Matthew and his colleagues place great importance on the fact that their unit is self-contained, this appears to be much more difficult to justify when there are only half this number of beds. It is much more likely in the district general hospitals that the unconscious patients will first be admitted to the intensive care units, especially as the principal treatment now is supportive. The conscious patients will probably be admitted firstly to the medical wards and then, if necessary, transferred rapidly to a short stay psychiatric unit, preferably within the same hospital. This pattern is similar to that recommended in the Hill report. The effect of increasing the catchment area in order to make a self-contained unit viable, and to justify the additional staff and equipment, would in many areas lead to a delay in the patient's arrival in hospital. Though there are no data on the effect of time and distance on the mortality rate, the excellent success rate in those patients who reach hospital alive is evidence enough not to make the centres too far apart.

There is, however, no doubt from this paper that the designation of a consultant in charge is an extremely important recommendation, which results in better co-ordination of the different branches of medicine that may be concerned in resuscitation and rehabilitation.

Since, therefore, it appears that virtually no additional resources are necessary to treat acute poisoning in district general hospitals with accident and emergency departments, the designation of a poisoning treatment centre need not be subject to the demands of other hospital services on available resources.

\section{Maintenance Haemodialysis}

The two years since our last leading article $^{1}$ on the management of end-stage renal failure has been a time of consolidation rather than of innovation in the field of maintenance haemodialysis. By March 1969 4,302 patients had started on treatment in Europe ${ }^{2}$ compared to 1,163 in 1967. The absence of a significant fall in mortality (32\% in 1967, $30.5 \%$ in 1969) is disappointing, but may in part be an effect of high mortality figures from newly opened units.

The excellent results which may be achieved in a wellequipped dialysis centre with experienced staff are shown by a recent report ${ }^{3}$ from $J$. R. Curtis and his colleagues. Their total experience was 41 patient-years ; 32 patients started on treatment and 3 died. Psychosocial rehabilitation is just as important a measure of successful dialysis as survival, and only four of their patients failed to resume useful employment. Though depression, anxiety, and frustration were common, no patient required psychiatric treatment.

Curtis and his colleagues also give a comprehensive account of the technical and medical difficulties of long-term haemodialysis. One of the most troublesome problems besetting patients and their medical attendants is the arteriovenous shunt. With scrupulous attention to detail a mean survival rate of 17.0 months for arterial cannulae and 9.6 months for venous cannulae was obtained. The incidence of clotting in the shunt was shown to be reduced by long-term treatment with anticoagulants. In many other units the survival of shunts is less satisfactory, and the use of a Brescia-Cimino fistula ${ }^{4}$ instead is increasing in popularity. An outbreak of hepatitis affected 15 patients (with one death) but no members of the staff. An incubation period of seven to nine weeks and modification of the course of the disease by gammaglobulin suggested that this was infectious hepatitis rather than serum hepatitis. Blood transfusion requirements were reduced from 2.5 units to 0.34 unit per patient-month by a policy of withholding transfusion until major symptoms of anaemia appeared. Renal osteodystrophy may progress in spite of otherwise adequate dialysis, ${ }^{5}$ and it is encouraging to note that Curtis and his colleagues found no evidence of progressive bone decalcification or metastatic calcification in their patients. A dialysate calcium concentration of $6 \mathrm{mg} . /$ $100 \mathrm{ml}$. appears to be critical ${ }^{6}{ }^{7}$; aluminium hydroxide was given when the calcium-phosphate product exceeded 75, and vitamin $\mathrm{D}$ was rarely used. One patient required parathyroidectomy. No patient developed peripheral neuropathy after starting dialysis, and pre-existing neuropathy regressed. Hypertension was controlled by dialysis and dietary salt restriction in all but two patients, in whom bilateral nephrectomy was eventually performed.

Clearly, haemodialysis can offer a worth-while life to many patients who would otherwise die of renal failure. In England and Wales some 600 patients are being treated at present, but every year over 2,000 prospective patients die. ${ }^{8}$ Selfdialysis by patients in their own homes ${ }^{9}$ reduces the pressure on hospital beds and staff, and it has the additional advantages of decreasing the patient's feeling of dependency and of a lower incidence of complications of dialysis. For these reasons most units in Britain are now concentrating on training for home dialysis, though not all patients are suitable, and indeed its difficulties may have been underrated. ${ }^{10}$ Patients dialysing themselves at home still require the support of a dialysis centre, so the number of patients that can be managed by any one unit is limited. When all the present and planned units in England and Wales are fully operational their maximum total complement is unlikely to exceed 3,000 patients. So with current resources only a minority of the patients who could benefit will receive treatment with maintenance haemodialysis.

The number of patients who have been treated by renal transplantation is as yet too small to have lessened the demand for dialysis to any extent. But a successful transplant is preferable to lifelong dialysis; and the results of transplan-

1 British Medical fournal, 1967, 1, 581.

Drukker, W., Haagsma-Schouten, W. A. G., Alberts, C., and Spoek, M. G., Proceedings of the European 'Dialysis and Transplant Association, 1969, 6, in press.

- Curtis, J. R., et al., Quarterly fournal of Medicine, 1969, 38, 49.

Brescia, M. J., Cimino, J. E., Appel, K., and Hurwich, B. J., New England fournal of Medicine, 1966, 275, 1089.

- Hampers, C. L., and Schupak, E., Long Term Hemodialysis, 1967, London, Heinemann.

Kaye, M., Mangel, R., and Neubauer, E., Proceedings of the European Dialysis and Transplant Association, 1966, 3, 17.

- Wing, A. J., British Medical fournal, 1968, 4, 145. 8 Kerr, D. N. S., Proceedings of the Royal Society of Medicine, 1967,
60, 1195.

- Baillod, R. A., Comty, C., Ilahi, M., Konotey-Ahulu, F. I. D., Sevitt, L., and Shaldon, S., Proceedings of the European Dialysis and Transplant Association, 1965, 2,99.

1 Smith, E. K. M., Curtis, J. R., McDonald, S. J., and de Wardener, H. E., Lancet, 1969, 1, 614.

1 Calne, R. Y., et al., British Medical fournal, 1968, 2, 404.

Marshall, V., Kincaid-Smith, P., Morris, P. J., Saker, B., and Eremin, J., Lancet, 1968, 2, 927.

1s Pletka, P., et al., Lancet, 1969, 1, 1. Woodruff, M. F. A., Nolan, B., Robson, J. S., and MacDonald, M. K.,
Lancet, 1969, 1, 6. 